\title{
miREIA - an immunoassay method for the assessment of microRNA levels in tumor tissue - a pilot study. The impact of miR-93-5p, miR-142-5p, and IFNy on PD-L1 level in colorectal cancer
}

\author{
Miriam Dawidowicz ${ }^{\#}$, Agnieszka Kula1\#, Sylwia Mielcarska1\#四, Paweł Kiczmer², \\ Karolina Gołąbek1', Zofia Ostrowska1', Dariusz Waniczek ${ }^{3 *}$ and Elżbieta Świętochowska1* \\ 1Department of Medical and Molecular Biology, Faculty of Medical Sciences in Zabrze, Medical University of Silesia, Zabrze, Poland; 2 Depart- \\ ment and Chair of Pathomorphology, Faculty of Medical Sciences in Zabrze, Medical University of Silesia, Zabrze, Poland; ${ }^{3}$ Department of \\ Surgical Nursing and Surgery Propedeutics, General, Colorectal and Trauma Surgery, Faculty of Health Sciences in Bytom, Medical University of \\ Silesia, Bytom, Poland
}

Colorectal cancer (CRC) is the second and third most common cancer in females and males, respectively. The PD-L1/PD-1 immune checkpoint is an important source of immunosuppression in the tumor microenvironment and is associated with IFNy. Recent studies revealed that a significant number of tumor-suppressive miRNAs can regulate the expression of PD-L1. The objective quantification of selected microRNAs using the miREIA method in CRC tissue was performed. We investigated the role of miR-93-5p and miR-142-5p expression and the levels of IFNy in regulating the expression of PD-L1 in tumor and margin tissues of CRC in relation to the histological grade, TNM classification, and tumor localization. 37 samples of tumor and margin tissues from CRC patients were evaluated. MiR-93-5p and miR-142-5p levels were measured using a novel method for the quantitative measurement of human microRNA (miREIA). The concentrations of PD-L1 and IFNy were determined using ELISA kits. We found higher concentrations of miR-93-5p, PD-L1, and IFN $\gamma$ in tumor samples compared to the tumor margin samples. A significant correlation was found between PD-L1 and IFNy levels in tumor and margin specimens; between miR-142-5p and miR-93-5p levels in tumor and margin specimens. A higher level of miR-93-5p was found in tumor margin tissues on the left side of the colon. Patients with distant metastases were characterized by higher miR-93-5p concentration compared to patients without metastases. CRC is an important source of PD-L1, IFN $\gamma$, and miR-93-5p expression. Understanding the mechanisms underlying intratumoral PD-L1 expression may create new opportunities for targeted immunotherapy of colorectal cancer.

Keywords: miREIA, miR-93-5p, miR-142-5p, PD-L1, IFN $\gamma$, colorectal cancer

Received: 28 October, 2020; revised: 07 February, 2021; accepted: 09 February, 2021; available on-line: 07 April, 2021

$\square$ e-mail: sylwiamielcarska@gmail.com

\#All these authors contributed equally

*Senior authors

Abbreviations: CRC, colorectal cancer; miREIA, miRNA enzyme immunoassay; PD-L1, Programmed death-ligand 1; IFN $\gamma$, Interferon gamma; miR-93-5p, microRNA-93-5p; miR-142-5p, microRNA$142-5 p$

\section{INTRODUCTION}

Colorectal cancer (CRC) is a heterogeneous disease that affects the colon and rectum, which are parts of the gastrointestinal system. It is one of the most serious illnesses irrespectively of gender. It has been recognized as the second and third most common cancer in females and males, respectively. According to Global Cancer Statistics, the prevalence of CRC in 2018 was about $6.1 \%$ of new cancer cases (Rawla et al., 2019). It is the second leading cause of cancer-related death worldwide (Keum and Giovannucci, 2019). A $60 \%$ increase in CRC cases is expected worldwide by 2030 (Al-Zalabani, 2020).

The discovery of the PD-1/PD-L1 immune checkpoint had an immense impact on novel cancer therapies. Overexpression of PD-L1 has already been confirmed in many types of cancer, including lung, hematopoietic, esophageal, gastric, and colorectal cancer. PD-L1 expressed on tumor cells interacts with PD-1 on tumor-infiltrating lymphocytes, such as $\mathrm{T}$ cells, $\mathrm{B}$ cells, and myeloid cells. This interaction can activate the down-stream signaling of PD-1 receptors in $\mathrm{T}$ cells, thus inhibiting proliferation, cytokine generation and cytotoxity of $\mathrm{T}$ cells. This down-regulation is used by tumors to protect themselves from immune attack (Wu et al., 2019).

Recent studies revealed that interferon-gamma (IFN $\gamma$ ), which is a proinflammatory cytokine, and a significant number of tumor-suppressive microRNAs play an important role in cancer development and can regulate the expression of PD-L1, which is a component of the immune checkpoint (Wang et al., 2017b). Inflammatory cells, especially activated T lymphocytes, are usually the major source of IFN $\gamma$. Probably, PD-L1 in tumor cells is up-regulated in response to inflammation and suppresses the excessive immune response. This mechanism allows tumors to evade immunity (Wang et al., 2017b).

There are many studies on the correlation between dysregulated microRNAs and the abnormal regulation of signaling pathways involved in the initiation and progression of CRC.

Additionally, it was confirmed that microRNAs can target PD-L1 (To et al., 2018).

MicroRNAs are small single-stranded non-coding RNAs of about 18-22 nucleotides in length, that regu- 
late up to $30 \%$ of human genes (Petrocca et al., 2008; Tsang et al., 2015). They have an impact on gene expression at the transcriptional and post-transcriptional levels by completely or incompletely binding to the 3'-UTR of their target gene messenger RNA and by repressing the translation or promoting the degradation of the target gene to exert biological functions (Wang et al., 2017d). They are involved in several biological processes, including proliferation, metabolism, apoptosis, and inflammation. Apart from their crucial role in physiological processes, microRNAs are frequently dysregulated in human cancers (Tsang et al., 2015; To et al., 2018).

The gene encoding miR-142-5p is located on human chromosome 17 . Recent studies reported that miR-142$5 \mathrm{p}$ is aberrantly expressed in different pathological conditions, including cancers (Islam et al., 2018). Yao and others (Yao et al., 2019) showed that miR-142-5p regulated pancreatic cancer cell proliferation and apoptosis by regulating RAP1A.

MiR-93-5p is a member of the miR-106b-25 cluster, its sequence is 23 nucleotides in length and its gene is located on chromosome 7. MiR-93-5p was reported to be up-regulated in several cancer types such as hepatocellular, lung, gastric, and particularly colorectal cancer. Wang and others (Wang et al., 2017c) reported that miR-93-5p increases multidrug resistance in CRC cells by down-regulating cyclin-dependent kinase inhibitor $1 \mathrm{~A}$ gene expression.

It was suggested that miR-93-5p and miR-142-5p can regulate PD-L1 expression by biding to its 3'UTR. However, the role of this pathomechanism in CRC remains largely unknown, and hence this study was undertaken (Cioffi et al., 2017; Jia et al., 2017; Wang et al., 2017b; Chen et al., 2020).

It was reported that microRNAs may regulate PDL1 expression in a direct and indirect manner. Some microRNAs (miR-93-5p, miR-142-5p, miR-15a, miR15b, miR 106b, miR 142-5p, miR 193a-3p, miR-200, miR 324-5p, miR 338-5p, miR-424, miR-513) directly target the 3'-UTR of PD-L1 mRNA whereas other microRNAs (including miR-181a, miR-378, miR-27a, miR-23b, miR-10a) might regulate the PDL1 level by affecting pathways of PD-L1-related genes such as FN- $\gamma$, IFNGR, IRF1, PTEN, JAK, STAT, PI3K, AKT, MEK and ERK (Wang et al., 2010; Ma et al., 2011; Yu et al., 2015; Kao et al., 2017; Wang et al., 2017b).

We used miREIA - an immunoassay method for quantification of $\mathrm{miR}-142-5 \mathrm{p}$ and $\mathrm{miR}-93-5 \mathrm{p}$ in the samples of colorectal tumor tissue and surgical margin tissue. The method involves the hybridization of microRNA to a complementary biotinylated DNA oligonucleotide probe. In this method, the DNA-RNA hybrids are then captured by a microtiter plate-immobilized monoclonal antibody specific to DNA/microRNA hybrids. In the next step standard ELISA techniques are used (Kappel et al., 2015). To assess the usefulness of the miREIA method for the absolute quantification of the miRNA in tumor tissue samples we chose miR-93-5p and miR-142-5p. The reason was that as of November 1, 2019, of the available miREIA kits, only these two microRNAs had binding sites on the 3'-U'TR side of the PD-L1 mRNA provided by TARGETSCAN.

Our study aimed to investigate the roles of miR93-5p and miR-142-5p expression and the levels of IFN $\gamma$ in regulating the expression of PD-L1 in tumor and margin tissues of CRC in relation to the histological grade, TNM classification and tumor localization.

\section{MATERIALS AND METHODS}

\section{Study sample}

The samples from 37 patients obtained during surgery due to CRC were included in the study. Patients were treated in the 1st Specialistic Hospital in Bytom, Poland (approval of the Research Ethics Committee No. KNW/0022/KB1/42/III/14/16/18). The collected specimens included colorectal tumor tissues and surgical margin tissues. Patients were enrolled in the study after meeting the following criteria: age $>18$ years, signed written consent, histological confirmation of colorectal adenocarcinoma, and surgical "tumor-free" margin tissue. The exclusion criteria were as follows: no consent to participate in the study, tumors other than adenocarcinoma, tumors with involved margins, age $<18$ years. To classify the cancer stage, the TNM staging system and grading were used. Research sample characteristics are presented in Table 1.

\section{Sample preparation for the evaluation of microRNA level}

Upon collection, the fragments of the tumor tissue and surgical margin tissue were stored in RNAlater Stabilization Solution (Ambion, Inc., USA) at $-80^{\circ} \mathrm{C}$. The samples were prepared for RNA isolation by prior tissue disruption. The samples were homogenized

Table 1. Patient characteristics

\begin{tabular}{|c|c|c|c|}
\hline & Female & Male & \\
\hline & 16 & 21 & 37 (100\%) \\
\hline Age & $62.56 \pm 11.5$ & $61.91 \pm 9.14$ & $62.19 \pm 10.08$ \\
\hline \multicolumn{4}{|c|}{$\mathrm{T}$ parameter } \\
\hline T1 & $0(0 \%)$ & $0(0 \%)$ & $0(0 \%)$ \\
\hline $\mathrm{T} 2$ & $7(43.75 \%)$ & $3(14.29 \%)$ & $10(27.03 \%)$ \\
\hline T3 & $7(43.75 \%)$ & 12 (57.14\%) & 19 (51.35\%) \\
\hline T4 & $2(12.5 \%)$ & $6(28.57 \%)$ & $8(21.62 \%)$ \\
\hline \multicolumn{4}{|c|}{$\mathrm{N}$ parameter } \\
\hline No & $8(50 \%)$ & $9(45 \%)$ & $17(45.95 \%)$ \\
\hline N1 & $6(37.50 \%)$ & $6(30 \%)$ & $12(32.43 \%)$ \\
\hline N2 & $2(12.50 \%)$ & $5(25 \%)$ & 7 (18.92\%) \\
\hline \multicolumn{4}{|c|}{ M parameter } \\
\hline MO & 15 (93.75\%) & $14(70.00 \%)$ & 19 (51.35\%) \\
\hline M1 & $1(6.25 \%)$ & $6(30.00 \%)$ & 7 (18.92\%) \\
\hline \multicolumn{4}{|c|}{ TNM stage } \\
\hline 1 & $6(37.50 \%)$ & $2(9.52 \%)$ & $8(21.62 \%)$ \\
\hline II & $2(12.50 \%)$ & $6(28.57 \%)$ & $8(21.62 \%)$ \\
\hline III & $7(43.75 \%)$ & $7(33.33 \%)$ & $14(37.84 \%)$ \\
\hline IV & 1 (6.25\%) & $6(28.57 \%)$ & 7 (18.92\%) \\
\hline \multicolumn{4}{|c|}{ Grading } \\
\hline G1 & $1(6.25 \%)$ & $0(0.00 \%)$ & $1(2.70 \%)$ \\
\hline $\mathrm{G} 2$ & $15(93.75 \%)$ & $21(100 \%)$ & $36(97.30 \%)$ \\
\hline G3 & $0(0 \%)$ & $0(0 \%)$ & $0(0 \%)$ \\
\hline
\end{tabular}


using FastPrep ${ }^{\circledR}-24$ Classic Instrument (MP Biomedicals, Solon, CA, USA) at $11,000 \mathrm{rpm}$ in Lysis Buffer (BioVendor, Czech Republic) in Lysing Matrix D Column (MP Biomedicals, Solon, CA, USA). MiRIA RNA Isolation Kit (BioVendor, Czech Republic) was used to isolate RNA. The total RNA concentration was determined using NanoPhotometer ${ }^{\circledR}$ P-Class (Implen $\mathrm{GmbH}$, Germany).

\section{Evaluation of hsa-miR-142-5p and hsa-miR-93-5p levels}

MicroRNA levels in the isolates were assessed by an enzyme immunoassay for the quantitative measurement of human microRNA. It is a novel method that involves the hybridization of microRNA isolated from the patient sample to a complementary biotinylated DNA probe (miREIA). We conducted the assay (miREIA) according to the manufacturer's instructions. The level of hsa-miR-142-5p was assayed using the human hsa-miR-142-5p miREIA kit (BioVendor, Czech Republic) with a sensitivity of $0.13 \mathrm{amol} / \mu \mathrm{l}$. The level of hsa-miR-93-5p was determined using the hsa-miR-93-5p miREIA kit (BioVendor, Czech Republic) with a sensitivity of $0.13 \mathrm{amol} / \mu \mathrm{l}$. Hybridization was conducted using Eppendorf 5333 MasterCycler Thermal Cycler (Eppendorf AG, Germany). The absorbance of the samples was determined using a Universal Microplate Spectrophotometer ( $\mu$ QUANT, Biotek Inc., Winooski, VT, USA) at a wavelength of $450 \mathrm{~nm}$. The obtained results were recalculated to the corresponding total RNA level and presented as ng/ $\mu l$ of RNA.

\section{Preparation of samples for the evaluation of PD-L1 and INFy levels}

Fragments of the tumor tissue and surgical margin tissue were weighted and homogenized using a PRO 200 homogenizer (PRO Scientific Inc., USA) at 10000 $\mathrm{rpm}$ in nine volumes of phosphate-buffered saline (BIOMED, Poland). The suspensions were sonicated with an ultrasonic cell disrupter (UP 100, Hilscher, Germany). Subsequently, the homogenates were centrifuged at $12000 \mathrm{rpm}$ for $5 \mathrm{~min}$ at $4^{\circ} \mathrm{C}$. The total protein level was determined using a Universal Microplate Spectrophotometer ( $\mu$ QUANT, Biotek Inc., Winooski, VT, USA).

\section{Evaluation of PD-L1 and INF- $\gamma$ levels}

To assess the levels of the investigated proteins, an enzyme-linked immunosorbent assay (ELISA) was used according to the manufacturer's instructions. PD-L1 level was evaluated using a human PD-L1 ELISA kit (Cloud Clone, China) with a sensitivity of $0.057 \mathrm{ng} / \mathrm{ml}$. INF $\gamma$ level was determined using the human INF $\gamma$ level ELISA kit (KHC4022, Germany) with a sensitivity of $4 \mathrm{pg} / \mathrm{ml}$. The absorbance of the samples was determined using a Universal Microplate Spectrophotometer ( $\mu$ QUANT, Biotek Inc., Winooski, VT, USA). The measurement was conducted at a wavelength of $450 \mathrm{~nm}$. The obtained results were recalculated to the corresponding total protein level and presented as $\mathrm{g} / \mathrm{g}$ of protein.

\section{Statistical analysis}

Data distribution was assessed using the ShapiroWilk test. The log transformation of the levels of the examined molecules provided a better fit to the Gaussian distribution. Data are presented as mean \pm S.D. for the variables with normal distribution and as median with interquartile range for the variables with non-normal distribution. To compare the tumor and margin levels, the paired Student's $t$-test was used. Independent variables were compared using the Student's $t$-test. Pearson's coefficient was used to assess the relationships between the examined variables with normal distribution. The Spearman's correlation coefficient was used for variables with non-normal distribution. $P$ values $<.05$ were considered statistically significant. The statistical analysis was performed using STATISTICA 13 software (TIBCO Software Inc., Palo Alto, CA, USA).

\section{RESULTS}

We found significantly higher concentrations of miR-93-5p, PD-L1 and IFN $\gamma$ in the tumor samples compared to surgical margin tissues (Table 2). The difference in miR-142-5p concentrations between tumor and margin tissues was not significant (Table 2).

Table 2. Levels of miR-142-5p, miR-93-5p, PD-L1, and IFN $\gamma$ molecules in tumor and margin tissues; miR levels are presented as log-transformed values ( $\mathrm{ng} / \mathrm{\mu l}$ ) and protein levels as $\mathrm{g} / \mathrm{g}$.

We observed significantly higher concentrations of miR-93-5p, PD$\mathrm{L} 1$ and IFNY in the tumor samples compared to surgical margin tissues.

\begin{tabular}{lccccc}
\hline & Tumor & \multicolumn{4}{l}{ Margin } \\
\cline { 2 - 5 } & Mean & S.D. & Mean & S.D. \\
\hline $\log$ miR-142-5p & -5.49 & 0.42 & -5.37 & 0.38 & 0.191 \\
\hdashline $\log$ miR-93-5p & -5.27 & 0.29 & -5.44 & 0.36 & 0.029 \\
\hdashline $\log$ PD-L1 & -4.31 & 0.30 & -4.47 & 0.23 & 0.002 \\
\hdashline $\log$ IFNY & -8.01 & 0.31 & -8.15 & 0.35 & 0.003 \\
\hline
\end{tabular}

We found a significant correlation between miR-142$5 \mathrm{p}$ and miR-93-5p concentrations in tumor and margin tissues (Table 3). A significant correlation was also found between PD-L1 and IFN $\gamma$ levels in tumor and margin specimens (Table 3). Additionally, IFN $\gamma$ levels in the tumor were correlated with PD-L1 levels in margin tissues (Table 3).

Patients with distant metastases were characterized by higher miR-93-5p concentration compared to patients without metastases (Fig. 1). We found a higher level of

Table 3. Correlation between the levels of the examined molecules.

We observed a significant correlation between miR-142-5p and miR-93-5p levels in tumor and margin tissues, as well as between PD-L1 and IFNY levels in tumor and margin tissue. Furthermore, IFNY concentrations in the tumor were associated with PD-L1 concentrations in margin tissues.

\begin{tabular}{lll}
\hline Pair of variables & $\mathrm{R}$ & $\mathrm{P}$ \\
\hline $\begin{array}{l}\text { Tumor log miR-93-5p and tumor } \\
\text { log miR-142-5p }\end{array}$ & 0.52 & 0.002 \\
\hline $\begin{array}{l}\text { Margin log miR-93-5p and margin } \\
\text { log miR-142-5p }\end{array}$ & 0.40 & 0.022 \\
\hline Margin log PDL 1 and margin log IFNy & 0.72 & $<0.0001$ \\
\hline Tumor log IFNy and margin log IFNy & 0.69 & $<0.0001$ \\
\hdashline Tumor log PDL 1 and tumor log IFNy & 0.57 & 0.001 \\
\hline Margin log PDL 1 and tumor log IFNy & 0.43 & 0.012 \\
\hline
\end{tabular}




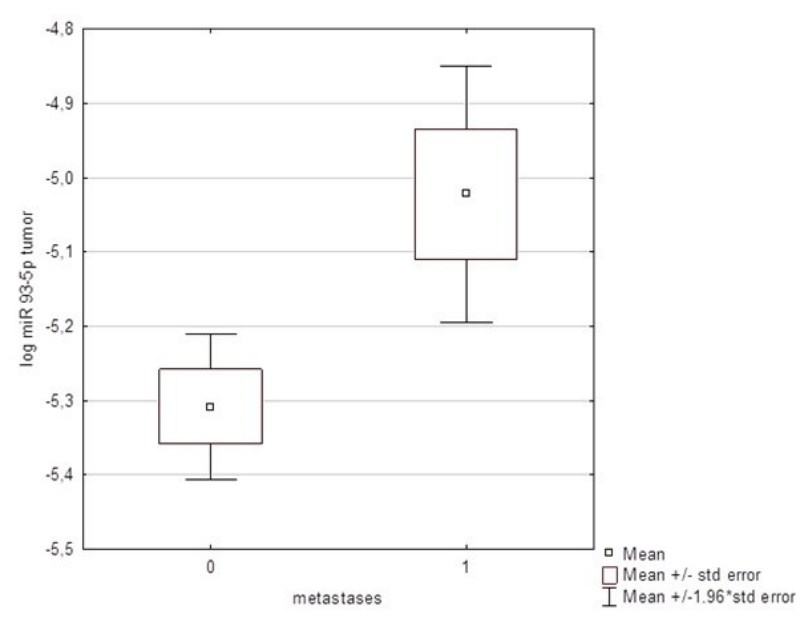

Figure 1. Comparison of miR-93-5p tumor levels in patients with $(1) /$ without $(0)$ metastases $(P=0.015)$.

Patients with distant metastases were characterized by higher miR-93-5p concentration compared to patients without metastases.

miR-93-5p in the margin tissue of tumors located on the left side of the colon (Fig. 2).

\section{DISCUSSION}

Recently, the development of immune checkpoint therapy has been the most exciting event in the anti-cancer fight. The PD-1/PD-L1 immune checkpoint is the main target of this therapy. The overexpression of PDL1 in CRC has been widely studied and assessed (Kim et al., 2016; Lee et al., 2017; Berntsson et al., 2018; Korehisa et al., 2018; Valentini et al., 2018). As a result, several trials that targeted PD-L1 were initiated. Atezolizumab, durvalumab, avelumab are anti-PD-L1 antibodies that are still under investigation for the therapy of CRC patients (Yaghoubi et al., 2019). Unfortunately, no response was seen in CRC patients when atezolizumab was administered (Brahmer et al., 2012). Moreover, no partial response was obtained in patients treated with durvalumab or avelumab (Callahan et al., 2014; Heery et al., 2017). Therefore, a novel approach to down-regulate the PDL1 proteins and tumor immune evasion is sought.

Under physiological conditions, PD-L1 mRNA is commonly found in many tissue types. However, the PD-L1 protein was detected only in a few tissue types (e.g. tonsil tissue, the fraction of macrophage-like cells in the liver, lung and placenta). This finding indicates the existence of post-transcriptional PD-L1 regulation (Dong et al., 2002; Hirano et al., 2005). This regulation may occur via microRNAs, which is in line with previous studies (Cioffi et al., 2017; Jia et al., 2017; Wang et al., 2017b). MicroRNAs could be a novel therapeutic target for immune checkpoint modulation in anticancer therapy. In previous studies, the impact of miR-142-5p on PD-L1 levels was assessed in the mouse pancreatic ductal adenocarcinoma cell line Panc02 (Jia et al., 2017) and NSCLC cell lines (Wan et al., 2018). The influence of miR-93-5p on the investigated protein level was determined in mesenchymal stem cells (Cioffi et al., 2017). and in colorectal cancer tissues (Chen et al., 2020). In our study, we investigated the correlation between miR93-5p and the PD-L1 protein level as well as miR-142-

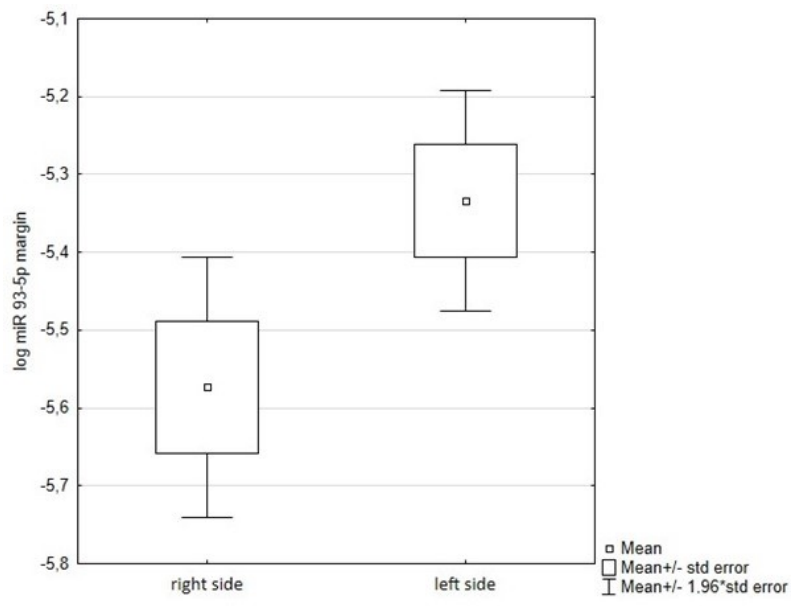

Figure 2. miR-93-5p levels in the margin tissues in patients with the tumor location in the colon $(P=0.042)$.

We observed a higher level of miR-93-5p in the margin tissue of tumors located on the left side of the colon.

$5 \mathrm{p}$ and the PD-L1 protein level to identify a new potential therapeutic target.

\section{RT-qPCR vs MiREIA}

To assess the levels of miR-93-5p and miR-142-5p we used a new method of microRNA quantification, i.e. microRNA enzyme immunoassay (miREIA). RT-qPCR is the gold standard in studies on microRNAs. In turn, we obtained the absolute amount of microRNA using the miREIA method (attomol/ $\mu \mathrm{l}$ ) whereas in RT-qPCR the quantification is relative (Stejskal et al., 2019). Nevertheless, the Pearson correlation coefficient for results obtained using miREIA method and RT-qPCR is higher than 0.9 (Stejskal et al., 2019). What is more, the efficiency of amplification in PCR technique can depend on the content of GC-rich sequences that do not denature efficiently during PCR procedure and may cause inaccurate results (Kalle et al., 2014). The microRNA enzyme immunoassay method does not require an amplification step, so the obtained results are not disturbed by this phenomenon. Moreover, comparative studies of both methods showed that the coefficients of variations $(\mathrm{CVs})$ of immunoassays are better than in RT-qPCR (Krepelkova et al., 2019; Stejskal et al., 2019). The RT step causes most of the variability produced in RT-qPCR (Ståhlberg et al., 2004), and based on the results of comparative studies, RT-qPCR is the least appropriate for microRNA quantification. However, it is still the most sensitive method and it definitely has a place in microRNA measurements (Krepelkova et al., 2019).

\section{The correlation between miR-93-5p and PD-L1}

In our study, we found a significant difference in miR-93-5p levels between cancer tissues and margin tissues $(P>0.05)$. However, we did not find any correlation between miR-93-5p levels and PD-L1 levels, which also differed significantly between cancer tissues and margin tissues ( $P>0.05)$. Coefii and others (Cioffi et al., 2017) provided evidence that the immune modulator (PD-L1) is a target of miR-93/106b in bone marrow (stromal) cells, monocytic myeloid-derived suppressor cells (MMDSC) and primary cancer cells. However, their sam- 
ple size was small $(n=4-5)$, the tests were conducted on mice and tumor cells obtained from murine pancreatic cancer models, which may partially explain the difference in the results. Chen and others (Chen et al., 2020) also found a negative correlation between miR-93-5p levels and PD-L1 in CRC tissues and the adjacent normal tissues $(n=125)$. The miR-93-5p levels were assessed by qRT-PCR, whereas the PD-L1 levels by immunohistochemistry (IHC). Their results showed that the miR93-5p was significantly down-regulated in CRC tissues compared to normal tissues. They found that miR-93-5p concentration was higher in patients negative for PD-L1 expression in IHC (Chen et al., 2020). However, our data revealed higher miR-93-5p levels in the tumor tissue. Moreover, we did not find a correlation between miR93-5p and PD-L1 levels. We did not, however, divide our group into patients with negative or positive PDL1 staining. Therefore, it may be necessary to separate a subgroup of PD-L1-positive and -negative patients based on IHC staining to clarify the relationship between miR93-5p and PD-L1.

\section{The correlation between miR-142-5p and PD-L1 and IFNy}

Some researchers reported that miR-142-5p played an important role in regulating the immune response. A relationship between miR-142-5p and PD-L1 expression was also confirmed experimentally. Jia et al. found that miR-142-5p could regulate PD-L1 expression by binding to its 3'UTR. They discovered that miR-142-5p overexpression in tumor cells inhibited the expression of PDL1 on tumor cells, which resulted in an increase in lymphocyte and IFN $\gamma$ levels. Those authors even reported that miR-142-5p overexpression could enhance anti-tumor immunity by blocking PD-L1/PD-1 pathway (Jia et al., 2017). Wikberg M.L. et al. in their study on the relationships between plasma levels of microRNA and clinicopathological factors proved that patients with a higher T-stage had significantly lower levels of 142-5p (Wikberg et al., 2018). On the other hand, a study in 125 CRC patients found that the expression of miR-142-5p in cancer tissue samples was significantly higher compared to noncancer samples. High miR-142-5p expression was associated with the biological aggressiveness of cancer cells (Islam et al., 2018). The above studies show inconclusive results related to the roles and levels of miR-142-5p in CRC.

In our study, no significant correlation was found between miR-142-5p expression and the concentrations of PD-L1 and IFN $\gamma$. Additionally, no difference was observed between tumor and margin tissues in terms of miR-142-5p concentrations. First of all, such results could be due to a small number of samples. Secondly, some studies which showed a positive relationship between miR-142-5p, PD-L1 and IFN $\gamma$ were conducted in exogenous pancreatic cancer cell lines. The conditions of our experiment were different due to another cancer type, tissues taken from patients during the surgery and other methods used for the quantitative measurement of microRNA expression, which probably had an impact on obtaining different results compared to the previous findings.

\section{The correlation between miR-93-5p and miR-142-5p}

There are two general mechanisms of regulating PDL1 expression by microRNA in cancers. Some microRNAs have been found to directly target the 3'UTR of PD-L1 mRNA, whereas indirect regulation is based on signaling molecules such as PTEN or IFR-1. Studies demonstrated that miR-142-5p and miR-93-5p regulated PD-L1 expression directly by binding to its 3'-UTR (Wang et al., 2017b). Our study demonstrated a significant correlation between miR-142-5p and miR-93-5p concentrations in tumor and margin tissues. This result may suggest that miR-93-5p and miR-142-5p are strongly involved in tumor progression. The presented correlation may be also related to a similar mechanism of regulating PD-L1 expression by miR-142-5p and miR-93-5p and may suggest their common involvement in this process. However, carefully designed experiments are needed to explain the cause of this correlation and the exact pleiotropic role of these microRNAs.

\section{The correlation between PD-L1 and INFY levels}

For many years, IFN $\gamma$ has been considered a crucial antitumor cytokine that is produced mainly by CD8-positive T Cells, natural killer cells, natural killer T cells, and macrophages (Mandai et al., 2016; Ayers et al., 2017). It inhibits tumor growth by inducing macrophage polarization, activation of cytotoxic $\mathrm{T}$ lymphocytes, modulation of dendritic cells, and up-regulation of MHC I expression (Cornetta et al., 1994; Mandai et al., 2016). Due to its antitumor activity, IFN $\gamma$ has been used clinically to treat a variety of tumors, including bladder cancer, melanoma and CRC (Mandai et al., 2016; Mojic et al., 2017). In clinical trials, interferon therapy provided conflicting outcomes and even aggravated the course of the disease (Mojic et al., 2017). Recent studies reported that the role of IFN $\gamma$ in tumor development has a dual aspect (Mandai et al., 2016). IFN $\gamma$ can promote tumor progression by up-regulating PD-L1 in different malignancies, including ovarian, breast, lung, gastric cancers, CRC, melanoma, and glioma.

It was reported that the PD-L1 gene promoter region has a response element to IRF-1, which is a mediator of the IFN $\gamma$ signaling pathway (Garcia-Diaz et al., 2017). These findings may explain the differences in response to IFN $\gamma$ treatment in clinical trials and the correlation between the levels of PD-L1 and IFN $\gamma$ in different types of cancer. The correlation between IFN $\gamma$ and PDL1 gene expressions measured by qPCR was observed in surgically resected $\mathrm{CRC}(P=0.03, \mathrm{r}=0.33)$ (Droeser et al., 2013). The level of PD-L1 correlates positively with the level of IFN $\gamma$ in patients with metastatic melanoma, gastric and ovarian cancers. Furthermore, it was reported that this correlation changes during anti-PD-1 therapy, whereas IFN therapy increases the level of PD-L1 (Chen et al., 2018; Mimura et al., 2018). Our results demonstrated the positive correlation between IFN $\gamma$ and PD-L1 levels not only in the tumor but also in the surrounding margins. It is consistent with results obtained from studies of various solid tumors as well as CRC (Droeser et al., 2013; Chen et al., 2018; Mimura et al., 2018). This finding shows the significance of normal tissue that does not contain cancer cells but is involved in immune processes in the tumor microenvironment and may play an essential role in tumor expansion.

\section{The correlation with clinicopathological features}

Some studies showed a correlation between the levels of PD-L1 and IFN $\gamma$ in the tumor or serum and clinicopathological parameters such as the TNM stage, histological grade and poor prognosis. However, the results are inconclusive. Droeser et al. demonstrated that in CRC the increased level of PD-L1 is associated with the presence of $\mathrm{CD} 8+\mathrm{T}$ cell infiltration, an early $\mathrm{T}$ stage, 
the lack of lymph node metastases, lower grading, the lack of vascular invasion, and a longer median overall survival (Droeser et al., 2013). On the contrary, other researchers indicated that PD-L1 overexpression in CRC was associated with advanced TNM stage, lymph node metastases, distant metastases, and decreased overall survival (Guo et al., 2018). Also in cervical squamous cell carcinoma, an increased level of PD-L1 correlated with advanced TNM stage, a decrease in the number of lymphocytes infiltrating the tumor and poor prognosis (Feng et al., 2018). Lack of association between the level of PD-L1 and clinicopathological parameters in our study may be due to a small, homogeneous study group. However, previous studies concerning the correlation between PD-L1 and clinicopathological features were contradictory and ambiguous. Therefore, perhaps PD-L1, despite its role in cancer-related immune response regulation, is not a suitable biomarker for clinicopathological features. This assumption seems to be also confirmed by a recent meta-analysis (Alexander et al., 2021).

Additionally, the association between miR-93-5p, miR$142-5 p$ and the clinical parameters in different types of cancers are not clear. The results of our study did not show any correlation between miR-142-5p and clinical parameters. However, it was reported that in CRC the level of miR-142-5p in the tumor was elevated and correlated with proximal CRC (Islam et al., 2018). In intrahepatic cholangiocarcinoma, the serum level of miR-142$5 \mathrm{p}$ was increased in patients with a more advanced TNM stage and higher histological grade (Wei et al., 2019). However, in breast cancer, a lower serum level of miR142-5p correlated with more advanced grading and larger tumor size (Ozawa et al., 2020).

Our data showed a significantly elevated margin level of miR-93-5p in patients with left-sided tumor location compared to the right-sided location. This association was not investigated in other studies, but miR-326 (another microRNA) was reported to be correlated with right-sided CRC (Moreno et al., 2019). Moreover, we found a positive correlation between miR-93-5p and metastases. The literature describes only the correlation of miR-93-5p with the phenomenon of multi-drug resistance, but the experiment was carried out on colorectal cancer cell lines (Wang et al., 2017c). To confirm the possible role of miR-93-5p as a biomarker of metastases in CRC and possibly other clinical parameters it is necessary to conduct a larger study. However, among other solid tumors, the dependence of clinical parameters on miR-93-5p was studied more extensively. In gastric and lung cancers, as well as head and neck squamous cell carcinoma, an increased level of miR-93-5p in the tumor was reported compared to the adjacent normal mucosa (Li et al., 2015; Lu et al., 2016; Ma et al., 2017). In nonsmall lung cancer, the level of miR-93-5p was associated with lymph node involvement and staging, whereas the overexpression of miR-93-5p in head and neck cancers correlated with the $\mathrm{T}$ parameter, lymph node involvement and advanced stage (Li et al., 2015; Lu et al., 2016). In gastric cancer, clear cell renal cell carcinoma and cervical cancer, miR-93-5p was also overexpressed in the tumor tissue and correlated with the stage of disease or poor patient prognosis (Guan et al., 2017; Wang et al., 2017a; Zhang et al., 2018).

\section{STUDY LIMITATIONS}

This study has potential limitations. First of all, it is limited by a small number of samples. Nevertheless, in our study, we obtained significant differences in the levels of the investigated molecules. Additionally, the mRNA expression and IHC staining were not evaluated for PD-L1. Therefore, further studies should focus on the analysis of mRNA expression of PD-L1 as well as determining the localization of PD-L1. It is crucial to establish the localization of PD-L1 by IHC to confirm that PD-L1 levels obtained in the ELISA test came from cancer cells and not from the tumor-infiltrating immune cells (myeloid cells). In future studies, we plan to analyze the mRNA expression of PD-L1 and perform microRNA quantification by RT-qPCR to compare microRNA levels with miREIA results. Additionally, we plan to evaluate proinflammatory cytokines and separate the subgroup of patients positive and negative for PD-L1, using IHC staining.

\section{CONCLUSION}

The miREIA method can be used to obtain absolute levels of microRNA in the colon tissue. PD-L1 plays an important role in tumor immune escape and it is up-regulated in CRC tissues. MiR-93-5p levels were significantly higher in surgical margin tissues, but they did not correlate with PD-L1 levels. However, miR-93-5p level correlated with metastases parameter thus could be considered as a potential biomarker of metastasis in CRC. Currently, little is known about the exact impact of microRNAs on the expression of PD-L1 in tumor cells. However, there are many directions in which research is conducted on the mechanisms of regulating the expression of many key proteins and signaling pathways involved in cancer development through microRNA. At the same time, therapeutic methods using microRNAs are being developed, many of them are in the pre-clinical stage. Moreover, the results of many preclinical studies allow for the creation of hypotheses and rationale for combining miRNA-based therapy with Immune Checkpoint Inhibitors (ICI) for increasing ICI efficacy or overcoming immunity to immune checkpoint blockade (Huemer et al., 2021). Both levels of miR-93-5p and miR-142-5p in the tumor and surgical margins are associated with and strongly involved in tumor progression. Further research and expansion of knowledge about these molecules may be potentially useful in cancer therapies. However, it is necessary to accurately determine all gene targets for a specific microRNA, as one microRNA can regulate the expression of many genes. MicroRNAs have received a lot of attention in the last decade and are widely studied. With the development of new molecular biology techniques like miREIA, qualitative and quantitative analysis of microRNAs becomes more adequate, easier, cheaper, and requires less specialized equipment.

\section{Acknowledgements}

We thank Biovendor for the methodological support in the quantitative measurement of microRNA.

\section{Funding source}

This study did not receive any funding.

\section{Conflict of interest}

The authors declare that they have no conflict of interest. 


\section{REFERENCES}

Alexander P G, McMillan D C, Park J H (2021) A meta-analysis of CD274 (PD-L1) assessment and prognosis in colorectal cancer and its role in predicting response to anti-PD-1 therapy. Crit Rev Oncol/Hematol 157: 103147. https://doi.org/10.1016/j.critrevonc.2020.103147

Al-Zalabani A (2020) Preventability of colorectal cancer in Saudi Arabia: fraction of cases attributable to modifiable risk factors in 20152040. Int I Environ Res Public Health 17. https://doi.org/10.3390/ ijerph17010320

Ayers M, Lunceford J, Nebozhyn M, Murphy E, Loboda A, Kaufman DR, Albright A, Cheng JD, Kang SP, Shankaran V, Piha-Paul SA, Yearley J, Seiwert TY, Ribas A, McClanahan TK (2017) IFN- $\gamma$ related mRNA profile predicts clinical response to PD-1 blockade. I Clin Invest 127: 2930-2940. https://doi.org/10.1172/JCI91190

Berntsson J, Eberhard J, Nodin B, Leandersson K, Larsson A H, Jirström K (2018) Expression of programmed cell death protein 1 (PD-1) and its ligand PD-L1 in colorectal cancer: Relationship with sidedness and prognosis. Oncoimmunology 7: e1465165. https://doi.or g/10.1080/2162402X.2018.1465165

Brahmer J R, Tykodi S S, Chow L Q M, Hwu W-J, Topalian S L, Hwu P, Drake C G, Camacho L H, Kauh J, Odunsi K, Pitot H C, Hamid O, Bhatia S, Martins R, Eaton K, Chen S, Salay T M, Alaparthy S, Grosso J F, Korman A J, Parker S M, Agrawal S, Goldberg S M, Pardoll D M, Gupta A, Wigginton J M (2012) Safety and activity of anti-PD-L1 antibody in patients with advanced cancer. $N$ Engl J Med 366: 2455-2465. https://doi.org/10.1056/NEJMoa1200694

Callahan MK, Ott P A, Odunsi K, Bertolini SV, Pan LS, Venhaus R R, Karakunnel JJ, Hodi FS, Wolchok JD (2014) A phase 1 study to evaluate the safety and tolerability of MEDI4736, an anti-PD L1 antibody, in combination with tremelimumab in patients with advanced solid tumors. JCO 32: TPS3120-TPS3120. https://doi. org/10.1200/jco.2014.32.15_suppl.tps3120

Chen G, Huang AC, Zhang W, Zhang G, Wu M, Xu W, Yu Z, Yang J, Wang B, Sun H, Xia H, Man Q, Zhong W, Antelo LF, Wu B, Xiong X, Liu X, Guan L, Li T, Liu S, Yang R, Lu Y, Dong L, McGettigan S, Somasundaram R, Radhakrishnan R, Mills G, Lu Y, Kim J, Chen YH, Dong H, Zhao Y, Karakousis GC, Mitchell TC, Schuchter LM, Herlyn M, Wherry EJ, Xu X, Guo W (2018) Exosomal PD-L1 contributes to immunosuppression and is associated with anti-PD-1 response. Nature 560: 382-386. https://doi. org/10.1038/s41586-018-0392-8

Chen Y-L, Wang G-X, Lin B-A, Huang J-S (2020) MicroRNA-93-5p expression in tumor tissue and its tumor suppressor function via targeting programmed death ligand-1 in colorectal cancer. Cell Biol Int 44: 1224-1236. https://doi.org/10.1002/cbin.11323

Cioffi M, Trabulo SM, Vallespinos M, Raj D, Kheir TB, Lin M-L, Begum J, Baker A-M, Amgheib A, Saif J, Perez M, Soriano J, Desco M, Gomez-Gaviro MV, Cusso L, Megias D, Aicher A, Heeschen C (2017) The miR-25-93-106b cluster regulates tumor metastasis and immune evasion via modulation of CXCL12 and PD-L1. Oncotarget 8: 21609-21625. https://doi.org/10.18632/oncotarget.15450

Cornetta K, Berebitsky D, Behnia M, Traycoff C, Srour EF, Sledge GW (1994) A retroviral vector expressing human interferon gamma upregulates MHC antigen expression in human breast cancer and leukemia cell lines. Cancer Gene Ther 1: 91-98. PMID: 7621246

Dong H, Strome SE, Salomao DR, Tamura H, Hirano F, Flies DB, Roche PC, Lu J, Zhu G, Tamada K, Lennon VA, Celis E, Chen L (2002) Tumor-associated B7-H1 promotes T-cell apoptosis: a potential mechanism of immune evasion. Nature Med 8: 793-800. https:// doi.org/10.1038/nm730

Droeser RA, Hirt C, Viehl CT, Frey DM, Nebiker C, Huber X, Zlobec I, Eppenberger-Castori S, Tzankov A, Rosso R, Zuber M, Muraro MG, Amicarella F, Cremonesi E, Heberer M, Iezzi G, Lugli A, Terracciano L, Sconocchia G, Oertli D, Spagnoli GC, Tornillo L (2013) Clinical impact of programmed cell death ligand 1 expression in colorectal cancer. Eur J Cancer 49: 2233-2242. https://doi. org/10.1016/j.ejca.2013.02.015

Feng M, Xu L, He Y, Sun L, Zhang Y, Wang W (2018) Clinical significance of PD-L1 (CD274) enhanced expression in cervical squamous cell carcinoma. Int J Clin Exp Pathol 11: 5370-5378. PMID: 31949618

Garcia-Diaz A, Shin DS, Moreno BH, Saco J, Escuin-Ordinas H, Rodriguez GA Zaretsky JM, Sun L, Hugo W, Wang X, Parisi G, Saus CP, Torrejon DY, Graeber TG, Comin-Anduix B, Hu-Lieskovan S, Damoiseaux R, Lo RS, Ribas A (2017) Interferon receptor signaling pathways regulating PD-L1 and PD-L2 expression. Cell Rep 19: 1189-1201. https://doi.org/10.1016/j.celrep.2017.04.031

Guan H, Li W, Li Y, Wang J, Li Y, Tang Y, Lu S (2017) MicroRNA-93 promotes proliferation and metastasis of gastric cancer via targeting TIMP2. PLoS ONE 12: e0189490. https://doi.org/10.1371/journal. pone. 0189490

Guo P-D, Sun Z-W, Lai H-J, Yang J, Wu P-P, Guo Y-D, Sun J (2018) Clinicopathological analysis of PD-L2 expression in colorectal can- cer. Onco Targets Ther 11: 7635-7642. https://doi.org/10.2147/OTT. S177329

Heery CR, O’Sullivan-Coyne G, Madan R A, Cordes L, Rajan A, Rauckhorst M, Lamping E, Oyelakin I, Marté JL, Lepone LM, Donahue RN, Grenga I, Cuillerot J-M, Neuteboom B, Heydebreck A von, Chin K, Schlom J, Gulley JL (2017) Avelumab for metastatic or locally advanced previously treated solid tumours (JAVELIN Solid Tumor): a phase 1a, multicohort, dose-escalation trial. Lancet Oncol 18: 587-598. https://doi.org/10.1016/S1470-2045(17)30239-5

Hirano F, Kaneko K, Tamura H, Dong H, Wang S, Ichikawa M, Rietz C, Flies DB, Lau JS, Zhu G, Tamada K, Chen L (2005) Blockade of B7-H1 and PD-1 by monoclonal antibodies potentiates cancer therapeutic immunity. Cancer Res 65: 1089-1096. PMID: 15705911

Huemer F, Leisch M, Geisberger R, Zaborsky N, Greil R (2021) miRNA-Based therapeutics in the era of immune-checkpoint inhibitors. Pharmacenticals (Basel) 14. https://doi.org/10.3390/ph14020089

Islam F, Gopalan V, Vider J, Lu C-T, Lam AK-Y (2018) MiR-142-5p act as an oncogenic microRNA in colorectal cancer: Clinicopathological and functional insights. Exp Mol Pathol 104: 98-107. https:// doi.org/10.1016/j.yexmp.2018.01.006

Jia L, Xi Q, Wang H, Zhang Z, Liu H, Cheng Y, Guo X, Zhang J, Zhang Q, Zhang L, Xue Z, Li Y, Da Y, Zhao P, Zhang R (2017) miR-142-5p regulates tumor cell PD-L1 expression and enhances anti-tumor immunity. Biochem Biophys Res Commun 488: 425-431. https://doi.org/10.1016/j.bbrc.2017.05.074

Kalle E, Kubista M, Rensing C (2014) Multi-template polymerase chain reaction. Biomol Detect Quantif 2: 11-29. https://doi.org/10.1016/j. bdq.2014.11.002

Kao SC, Cheng YY, Williams M, Kirschner MB, Madore J, Lum T, Sarun KH, Linton A, McCaughan B, Klebe S, van Zandwijk N, Scolyer RA, Boyer MJ, Cooper WA, Reid G (2017) Tumor suppressor microRNAs contribute to the regulation of PD-L1 expression in malignant pleural mesothelioma. J Thorac Oncol 12: 1421-1433. https://doi.org/10.1016/j.jtho.2017.05.024

Kappel A, Backes C, Huang Y, Zafari S, Leidinger P, Meder B, Schwarz H, Gumbrecht W, Meese E, Staehler CF, Keller A (2015) MicroRNA in vitro diagnostics using immunoassay analyzers. Clin Chem 61: 600-607. https://doi.org/10.1373/clinchem.2014.232165

Keum N, Giovannucci E (2019) Global burden of colorectal cancer: emerging trends, risk factors and prevention strategies. Nat Rev Gastroenterol Hepatol 16: 713-732. https://doi.org/10.1038/s41575-0190189-8

Kim JH, Park HE, Cho N-Y, Lee HS, Kang GH (2016) Characterisation of PD-L1-positive subsets of microsatellite-unstable colorectal cancers. Br J Cancer 115: 490-496. https://doi.org/10.1038/ bjc. 2016.211

Korehisa S, Oki E, Iimori M, Nakaji Y, Shimokawa M, Saeki H, Okano S, Oda Y, Maehara Y (2018) Clinical significance of programmed cell death-ligand 1 expression and the immune microenvironment at the invasive front of colorectal cancers with high microsatellite instability. Int J Cancer 142: 822-832. https://doi. org/10.1002/ijc.31107

Krepelkova I, Mrackova T, Izakova J, Dvorakova B, Chalupova L, Mikulik R, Slaby O, Bartos M, Ruzicka V (2019) Evaluation of miRNA detection methods for the analytical characteristic necessary for clinical utilization. BioTechniques 66: 277-284. https://doi. org/10.2144/btn-2019-0021

Lee K S, Kwak Y, Ahn S, Shin E, Oh H-K, Kim D-W, Kang S-B, Choe G, Kim W H, Lee H S (2017) Prognostic implication of CD274 (PD-L1) protein expression in tumor-infiltrating immune cells for microsatellite unstable and stable colorectal cancer. Cancer Immunol Immunother CII 66: 927-939. https://doi.org/10.1007/ s00262-017-1999-6

Li G, Ren S, Su Z, Liu C, Deng T, Huang D, Tian Y, Qiu Y, Liu $Y$ (2015) Increased expression of miR-93 is associated with poor prognosis in head and neck squamous cell carcinoma. Tumour Biol 36: 3949-3956. https://doi.org/10.1007/s13277-015-3038-6

Lu J, Xia C, Du C, Wu B, Zhou F, Zhou L, Xu D, Zhou F (2016) Up-regulation of MicroRNA-93 predicates advanced clinicopathological features and serves as an unfavorable risk factor for survival of patients with non-small cell lung cancer. 9. 10529-10535

Ma D-H, Li B-S, Liu J-J, Xiao Y-F, Yong X, Wang S-M, Wu Y-Y, Zhu H-B, Wang D-X, Yang S-M (2017) miR-93-5p/IFNAR1 axis promotes gastric cancer metastasis through activating the STAT3 signaling pathway. Cancer Lett 408: 23-32. https://doi.org/10.1016/j. canlet.2017.08.017

Ma T, Jiang H, Gao Y, Zhao Y, Dai L, Xiong Q, Xu Y, Zhao Z, Zhang J (2011) Microarray analysis of differentially expressed microRNAs in non-regressed and regressed bovine corpus luteum tissue; microRNA-378 may suppress luteal cell apoptosis by targeting the interferon gamma receptor 1 gene. J Appl Genet 52: 481-486. https://doi.org/10.1007/s13353-011-0055-z

Mandai M, Hamanishi J, Abiko K, Matsumura N, Baba T, Konishi I (2016) Dual faces of IFN $\gamma$ in cancer progression: a role of PD-L1 induction in the determination of pro- and antitumor immunity. 
Clin Cancer Res 22: 2329-2334. https://doi.org/10.1158/1078-0432. CCR-16-0224

Mimura K, Teh JL, Okayama H, Shiraishi K, Kua L-F, Koh V, Smoot DT, Ashktorab H, Oike T, Suzuki Y, Fazreen Z, Asuncion BR, Shabbir A, Yong W-P, So J, Soong R, Kono K (2018) PD-L1 expression is mainly regulated by interferon gamma associated with JAK-STAT pathway in gastric cancer. Cancer Sci 109: 43-53. https://doi.org/10.1111/cas.13424

Mojic M, Takeda K, Hayakawa Y (2017) The dark side of IFN- $\gamma$ : Its role in promoting cancer immunoevasion. Int J Mol Sci 19. https:// doi.org/10.3390/ijms19010089

Moreno EC, Pascual A, Prieto-Cuadra D, Laza VF, Molina-Cerrillo J, Ramos-Muñoz ME, Rodríguez-Serrano EM, Soto JL, Carrato A, García-Bermejo ML, Guillén-Ponce C (2019) Novel molecular characterization of colorectal primary tumors based on miRNAs. Cancers (Basel) 11. https://doi.org/10.3390/cancers11030346

Ozawa PMM, Vieira E, Lemos DS, Souza ILM, Zanata SM, Pankievicz VC, Tuleski TR, Souza EM, Wowk PF, Urban CA, Kuroda F, Lima RS, Almeida RC, Gradia DF, Cavalli IJ, Cavalli LR, Malheiros D, Ribeiro EMSF (2020) Identification of miRNAs enriched in extracellular vesicles derived from serum samples of breast cancer patients. Biomolecules 10. https://doi.org/10.3390/biom10010150

Petrocca F, Visone R, Onelli MR, Shah MH, Nicoloso MS, Martino I de, Iliopoulos D, Pilozzi E, Liu C-G, Negrini M, Cavazzini L, Volinia S, Alder H, Ruco LP, Baldassarre G, Croce CM, Vecchione A (2008) E2F1-regulated microRNAs impair TGFbeta-dependent cellcycle arrest and apoptosis in gastric cancer. Cancer Cell 13: 272-286. https://doi.org/10.1016/j.ccr.2008.02.013

Rawla P, Sunkara T, Barsouk A (2019) Epidemiology of colorectal cancer: incidence, mortality, survival, and risk factors. Prz Gastroenterol. 14: 89-103. https://doi.org/10.5114/pg.2018.81072

Ståhlberg A, Håkansson J, Xian X, Semb H, Kubista M (2004) Properties of the reverse transcription reaction in mRNA quantification. Clinical Chem 50: 509-515. https://doi.org/10.1373/ clinchem.2003.026161

Stejskal D, Hlozankova M, Sigutova R, Andelova K, Svagera Z, Svestak M (2019) Comparison of a new immunoassay and PCRbased method for quantification of microRNAs in whole blood. A pilot methodical study. Biomed Pap Med Fac Univ Palacky Olomouc Czech Repub 163: 39-44. https://doi.org/10.5507/bp.2018.080

To KK, Tong CW, Wu M, Cho WC (2018) MicroRNAs in the prognosis and therapy of colorectal cancer: From bench to bedside. World J Gastroenterol 24: 2949-2973. https://doi.org/10.3748/wjg. v24.i27.2949

Tsang FH-C, Au SL-K, Wei L, Fan DN-Y, Lee JM-F, Wong CC-L, Ng IO-L, Wong C-M (2015) MicroRNA-142-3p and microRNA$142-5 \mathrm{p}$ are downregulated in hepatocellular carcinoma and exhibit synergistic effects on cell motility. Frontiers Med 9: 331-343. https:// doi.org/10.1007/s11684-015-0409-8

Valentini AM, Di Pinto F, Cariola F, Guerra V, Giannelli G, Caruso ML, Pirrelli M (2018) PD-L1 expression in colorectal cancer defines three subsets of tumor immune microenvironments. Oncotarget 9: 8584-8596. https://doi.org/10.18632/oncotarget.24196
Wan J, Ling X, Peng B, Ding G (2018) miR-142-5p regulates CD4+ $\mathrm{T}$ cells in human non-small cell lung cancer through PD-L1 expression via the PTEN pathway. Oncol Rep 40: 272-282. https://doi. org/10.3892/or.2018.6439

Wang G, Wang Y, Teng M, Zhang D, Li L, Liu Y (2010) Signal transducers and activators of transcription-1 (STAT1) regulates microRNA transcription in interferon gamma-stimulated HeLa cells. PLoS ONE 5: e11794. https://doi.org/10.1371/journal.pone.0011794

Wang L, Yang G, Zhu X, Wang Z, Wang H, Bai Y, Sun P, Peng L, Wei W, Chen G, Li G, Zamyatnin AA, Glybochko PV, Xu W (2017a) miR-93-3p inhibition suppresses clear cell renal cell carcinoma proliferation, metastasis and invasion. Oncotarget 8: 82824-82834. https://doi.org/10.18632/oncotarget.20458

Wang Q, Lin W, Tang X, Li S, Guo L, Lin Y, Kwok HF (2017b) The Roles of microRNAs in regulating the expression of PD-1/PDL1 immune checkpoint. Int J Mol Sci 18. https://doi.org/10.3390/ ijms18122540

Wang S-J, Cao Y-F, Yang Z-Q, Jiang Z-Y, Cai B, Guo J, Zhang S, Zhang X-L, Gao F (2017c) MicroRNA-93-5p increases multidrug resistance in human colorectal carcinoma cells by downregulating cyclin dependent kinase inhibitor $1 \mathrm{~A}$ gene expression. Oncol Lett 13: 722-730. https://doi.org/10.3892/ol.2016.5463

Wang Z, Liu Z, Fang X, Yang H (2017d) MiR-142-5p Suppresses tumorigenesis by targeting PIK3CA in non-small cell lung cancer. Cell Physiol Biochem 43: 2505-2515. https://doi.org/10.1159/000484459

Wei G, Yuan Y, He X, Jin L, Di Jin (2019) Enhanced plasma miR$142-5 p$ promotes the progression of intrahepatic cholangiocarcinoma via targeting PTEN. Exp Ther Med 17: 4190-4196. https://doi. org/10.3892/etm.2019.7438

Wikberg ML, Myte R, Palmqvist R, van Guelpen B, Ljuslinder I (2018) Plasma miRNA can detect colorectal cancer, but how early? Cancer Med 7: 1697-1705. https://doi.org/10.1002/cam4.1398

Wu Y, Chen W, Xu ZP, Gu W (2019) PD-L1 Distribution and perspective for cancer immunotherapy-blockade, knockdown, or inhibition. Front Immunol 10: 2022. https://doi.org/10.3389/fimmu.2019.02022

Yaghoubi N, Soltani A, Ghazvini K, Hassanian SM, Hashemy SI (2019) PD-1/ PD-L1 blockade as a novel treatment for colorectal cancer. Biomed Pharmacother 110: 312-318. https://doi.org/10.1016/j. biopha.2018.11.105

Yao R, Xu L, Wei B, Qian Z, Wang J, Hui H, Sun Y (2019) miR$142-5 p$ regulates pancreatic cancer cell proliferation and apoptosis by regulation of RAP1A. Pathol Res Pract 215: 152416. https://doi. org/10.1016/j.prp.2019.04.008

Yu T, Liu L, Li J, Yan M, Lin H, Liu Y, Chu D, Tu H, Gu A, Yao M (2015) MiRNA-10a is upregulated in NSCLC and may promote cancer by targeting PTEN. Oncotarget 6: 30239-30250. https://doi. org/10.18632/ oncotarget.4972

Zhang X, Li F, Zhu L (2018) Clinical significance and functions of microRNA-93/CDKN1A axis in human cervical cancer. Life Sci 209: 242-248. https://doi.org/10.1016/j.lfs.2018.08.021 